\title{
IMPACTOS DO COVID-19: AS VISÕES E EXPERIÊNCIAS DE CRIANÇAS E JOVENS PORTUGUESES EM SITUAÇÃO DE ACOLHIMENTO RESIDENCIAL
}

\author{
Daiane Valasques ${ }^{\mathrm{i}}$ \\ Hugo Santos ${ }^{\text {ii }}$
}

\begin{abstract}
Resumo: A pandemia veio a questionar as estruturas mais fundacionais das nossas sociedades globais, incluindo o direito democrático à educação. A partir de uma abordagem participatória, envolvendo photovoiced, entrevistas e grupos focais, quis-se perceber quais os impactos psicológicos e educacionais da pandemia nos quotidianos de crianças e jovens em situação de acolhimento residencial. Os resultados indicam que as crianças e jovens se sentem isolados e entediados, chegando a ser difícil cumprir as regras para certos grupos. Esse stress estende-se às suas experiências educacionais que somadas à falta de recursos tecnológicos e técnicos da instituição, torna o direito a ser educado mais difícil. Chama-se a atenção para a necessidade de investir educacionalmente nestas instituições.
\end{abstract}

Palavras-chave: Acolhimento residencial; Crianças; Jovens; Educação; Covid-19.

\section{IMPACTS OF COVID-19: THE VISIONS AND EXPERIENCES OF PORTUGUESE CHILDREN AND YOUTH IN RESIDENTIAL CARE SITUATIONS}

\begin{abstract}
The pandemic came to question the most foundational structures of our global societies, including the democratic right to education. From a participatory approach, involving photovoiced, interviews and focus groups, we wanted to understand the psychological and educational impacts of the pandemic on the daily lives of children and young people in residential care. The results indicate that children and young people feel isolated and bored, making it difficult to comply with the rules. This stress extends to their educational experiences which, added to the institution's lack of technological and technical resources, makes the democratic right to be educated more difficult. Attention is drawn to the need to invest educationally in these institutions.
\end{abstract}

Keywords: Residential care; Children; Young; Education; Covid-19.

\section{Introdução}

Não será, porventura, exagero começar por afirmar como a recente pandemia de Covid19, hoje considerada como uma das maiores crises de saúde pública dos dois últimos séculos, veio abalar por completo os alicerces fundacionais das (nossas) ditas sociedades globais. Ao levar vários governos do mundo inteiro a decretarem profilaticamente medidas de exceção como cercos sanitários ou estados de emergência, e à consequente adoção de regras de 
confinamento, distanciamento e quarentena, obrigou a uma mudança radical de hábitos e costumes. Desse modo, a pandemiamodificou radicalmente as nossas interações e relações sociais mais básicas (incluindo afetivas e íntimas), assim como muitas liberdades fundamentais que não pensaríamos, em democracia, alguma vez ver limitadas. Os seus efeitos, contudo, não se confinaram a aspetos estritamente bioontológicos e sanitários, mas fez também levantaremse velhas questões filosóficas mais profundas e fundacionais sobre as condições materiais e identitárias da nossa existência. Por exemplo, qual o papel do Estado na gestão das nossas vidas? Como nos relacionamos com «outros» em sociedade? Qual o sentido da nossa própria materialidade? Como nos recorda o filósofo marxista Slavoj Žižek (2020), nunca a necessidade de reinventar as nossas formas de organização política, social e económica, o que incluiu as nossas democracias, esteve tão em cima da mesa como objeto de reflexão.

Esses questionamentos surgem, em parte, pelo abalo produzido nas estruturas mais básicas da sociedade. No campo educacional, por exemplo, as ordens governamentais para a interrupção da instrução presencial para a maioria dos alunos, levou a que as instituições educativas formais (escolas, universidades, entre outras instituições) fossem particularmente afetadas em todos os níveis de formação (DANIEL, 2020). Como forma de manter a continuidade do ensino nos moldes mais regulares possíveis, a educação remota ou on-line tornou-se uma das estratégias mais adotadas, nomeadamente através do uso de ferramentas próprias como aplicativos para reuniões por videoconferência, entre os quais a Zoom (ARCHIBALD, AMBAGTSHEER, CASEY, LAWLESS, 2019). Organizações não governamentais como, por exemplo, a UNESCO (2020a; 2020b), recomendaram o uso de programas de ensino a distância e plataformas e aplicativos educacionais abertos para que escolas e professores possam usar para alcançar os alunos remotamente.

No plano económico, as medidas de contenção levaram a paragensno trabalho o que produziu, consequentemente, fortes trepidações na economia global capitalista.Um dos problemas da pandemia foi exatamente a potencial recessão económica à escala planetária, sem precedentes,marcada pelo aumento exponencial do desemprego, da precariedade e da pobreza generalizada - ou seja, os "impactos escondidos".A questão sobre se a crise despoletada por um vírus desconhecido, com o qual ninguém estava preparado para lidar, veio a criar novas desigualdades, no sentido restrito do termo, a torna-las mais visíveisou agudizando-as, não é de resposta fácil, mas, sem dúvida, que o vírus expôs a vulnerabilidade de muitas comunidades de si já mais marginalizadas, assim como a fragilidade de muitas instituições de uma forma nunca antes vista. Isso tornou-se particularmente evidente nos dilemas em torno da sustentabilidade 
dos sistemas de saúde pública assim como nas parcas condições e recursos de muitas instituições sociais como, por exemplo, os lares de idosos.

O slogan "estamos todos no mesmo barco" surgiu como uma expressãosimbólica para ilustrar essa espécie de - para usar termos butlerianos (BUTLER, 2015) - precariedade generalizada, um sofrimento universalmente partilhado que condensa em si também uma consequente solidariedade global. Contudo, cedo se descobriu que a expressão não seria mais do que uma faláciauniversalista invisibilizadora que não servia para ocultar o facto objetivo e infeliz de que "alguns estão no mar e outros numa lancha", chamando-se a atenção para as desigualdades estruturais de género, raça e classe social (entre outras) que atingem certos grupos que sempre estiveram num estado de excecional vulnerabilidade.É o caso das crianças e jovens em situação de acolhimento, desprovidos da possibilidade de terem "vidas" e "percursos" "normais".

Como aconteceu em crises anteriores, as crianças encontram-se entre as principais vítimas de empobrecimento, carências alimentares e nutricionais mais generalizadas, negligência higiénica e sanitária, etc., que podem conduzir a situações de abandono escolar crescente, crescimento de comportamentos aditivos, perturbação da saúde mental pessoal e familiar ou exposição alargada a violência, abuso, exploração e trabalho infantil (CUEVASPARRA, STEPHANO, 2020; DELGADO, 2006; TOWNSEND, BERGER, REUPERT, 2019).Tradicionalmente já são considerados dos grupos sociais mais excecionalmente vulneráveis em situações de crise, e, embora sejam nas pessoas com idade mais avançada que se registe o maior índice de mortalidade pela doença (cf. LUDVIGSSON, 2020), não estão imunes aos impactos mais indiretos da pandemia.Se pensarmos nas crianças e jovens a viver um acolhimento residencial, pode-se admitir que se está a falar num dos grupos mais desprotegidos e em desvantagem da sociedade (MANNAY, STAPLES, HALLETT, ROBERTS, REES, EVAND, ANDREWS, 2019; TOWNSEND, BERGER, REUPERT, 2019), não sendo propriamente um segredo que as crianças e jovens que crescem em instituições (fechadas ou semiabertas) são muitas vezes estigmatizados e marginalizados aos mais diversos níveis (ARAÚJO; WILLIS, 2007; SILVA, 2011; GOFFMAN, 1952; GOFFMAN, 1961).

Paradoxalmente, são as menos ouvidas, impossibilitadas a lugares de fala pela estruturação adultocêntrica dos sistemas que conferem audibilidade. Quais as suas visões e perspetivas? Como estão a viver estas crianças e jovens a atual situação? E, sobretudo, como estão a ser educadas num contexto de maior fragilidade das instituições? Mesmo após 30 anos da Convenção dos Direitos da Criança pela Assembleia Geral das Nações Unidas, a infância, 


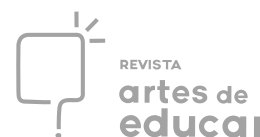

assim como a juventude, continuam a ser categorias desvalorizadas e subalternizadas (MANNAY,et al., 2019) e por isso é importante sondar o que pensam elas sobre a atual situação pandémica.

Este artigo explora as visões e experiências de crianças e jovens portugueses em acolhimento residencial sobre a atual situação de Covid-19 e os efeitos que a pandemia teve nos seus quotidianos, quer ao nível do bem-estar psicológico, quer ao nível do seu direito democrático à educação, nas suas diversas modalidades. Considerando que não existem (ainda) muitos estudos que explorem os efeitos deste vírus nas culturas juvenis contemporâneas, dado ser muito recente (cf. CUEVAS-PARRA, STEPHANO, 2020), pensa-se ser inovador abordar este grupo, considerando a tendência para ser esquecido como interlocutor válido sobre as suas realidades. Foge-se, pois, à tendência para interrogar apenas e somente os adultos - aquilo que Howard Becker chama "a hierarquia da credibilidade" (BECKER, 1967, p. 241) -, insistindo em querer conhecer a realidade a partir do olhar dos subordinados. Spivak (1988) icónica- e sarcasticamente perguntava: podem os subalternos falar? Podem as crianças e os jovens falar, perguntamos nós.

Como uma pesquisa alicerçada no campo multidisciplinar das Ciências da Educação não se tem pudor em convocar um conjunto de olhares teóricos que se situam em torno da Sociologia da Infância, da Sociologia da Educação e dos estudos culturais da Juventude.Interpelamos, pois, os jovens "nas mediações produzidas através de culturas juvenis, confrontando comunidades educativas não formais, mas também escolas" (ARAÚJO, WILLIS, 2007: 7), sempre os considerandoneste duplo (e, por vezes, tensional) papel de crianças e jovens e, simultaneamente, estudantes, e partilhando-se uma perspetiva que ao reconhecer a especificidade do seu olhar, a sua agência e participação, procura dar-lhes "a vez e a voz" (MENEZES; FERREIRA, 2014, p. 131), nos modos específicos de participarem e se construírem enquanto grupo social.Do ponto de vista organizacional, o artigo está estruturado em quatro diferentes secções: a primeira é dedicada ao enquadramento teórico, a segunda é dedicada à metodologia; na terceira apresenta-se os resultados e a discussão, e a quarta traz à liça as conclusões em jeito de recomendações.

\section{Crianças e jovens em situação de acolhimento residencial: breves considerações}

O direito à proteção do Estado é contemplado para todas as crianças e jovens afastados, temporária ou definitivamente, do meio familiar, conforme o previsto por vários tratados, 
convenções e organismos internacionais. A convenção das Nações Unidas sobre os Direitos da Criança (1989), por exemplo, prevê formas de acolhimento familiar ou residencial de crianças e jovens. Nos percursos de vida de muitas crianças e jovens, a ausência de uma efetiva retaguarda familiar ou de rede social de apoio na comunidade de origem constituem-se como problema sociais que determinam a necessidade do seu acolhimento, sob diversas modalidades (CARVALHO, TOMÁS, FERNANDES, 2019). Em Portugal, encontram-se 7.032 crianças e jovens em situação de acolhimento residencial e familiar, distribuídas pelas 14 respostas sociais que integram o sistema de acolhimento da Segurança Social. De acordo com o relatório CASA (2018), como possíveis causas para a sua institucionalização estão situações críticas de negligência, maus tratos, abuso sexual, abandono, mendicidade, suspeita de prostituição, entre outras situações, sendo estas crianças e jovens oriundas de famílias afetadas por múltiplos fatores de desvantagem social como pobreza e exclusão (cf. VALASQUES, 2018).

Previsto no Decreto-Lei n. ${ }^{\circ}$ 164/2019 que estabelece o regime de execução do acolhimento residencial, esteconsiste na colocação da criança ou do jovem aos cuidadosde uma instituição de acolhimento que disponha de instalações, equipamento de acolhimento e recursos humanos permanentes, devidamente dimensionados e habilitados, que lhe garanta os cuidados adequados às suas necessidades e bem-estar, com vista ao seu desenvolvimento integral, nos termos do artigo 41. ${ }^{\circ}$ da LPCJP (Lei de Proteção de Crianças e Jovens em Perigo). Para estes jovens, que se encontram nas ditas margens, o acesso à educação (formal, não formal ou informal), desde logo pelo seu caráter inertemente emancipatório, apresentam-se não só como um direito democrático a ser garantido, mas, sobretudo, como uma oportunidade crucial de sucesso, mobilidade e ascensão profissional e social. Vários estudos têm demostrado que este grupo apresenta uma maior probabilidade de vir a ter uma trajetória de vida marcada por situações de desvio, marginalidade e/ou exclusão social do que crianças e jovens não acolhidos (TOMAS, CARVALHO, FERNANDES, 2019; FONSECA, 2017; TOWNSEND, BERGER, REUPERT, 2020; VALASQUES, 2018), o que torna a necessidade de garantir a igualdade de mais e melhores oportunidades educacionais um imperativo democrático.

A relação deste grupo com a escola é marcada pelo desengajamento (ABRANTES, 2007; SILVA, 2011; WILLIS, 1999) e estes jovens são alvo de expectativas baixas que por sua vez dinamitam o seu investimento - aquilo que Erving Goffman (1952) chama de "arrefecimento das expetativas". Longe de ser neutral, a escola produz e/ou legitima relações de poder e hierarquias materiais e simbólicas, e o seu campo surge como um espaço disciplinador e normalizador de identidades, de grupos, de práticas, de saberes e de culturas. 
Segundo Pierre Bourdieu e Jean-Claude Passeron (1983), a escola produz e reproduz determinados tipos de capital, para além do económico, que beneficiam sobretudo grupos que estão familiarizados com esses tipos de capital. Nessa linha, os saberes valorizados pelos conteúdos educativos formais têm-se estruturado a partir dos pressupostos presumíveis da figura educacional que interessa - masculina, branca, heterossexual, de classe média, física e psicologicamente eficiente.

Nem sempre se tem conhecimento de como os processos e práticas educativas são interpretadas e vividas dentro destes contextos institucionais, tradicionalmente mais fechados. Como consequência, a maior parte dos estudos tem focado as transições e menos as experiências in loco, embora se assuma haver uma tendência para descurar e negligenciar o potencial educativo destas instituições que se defrontam constantemente com falta de meios, recursos e condições.

A própria pandemia do COVID-19 veio também a fazer questionar que garantias tem estas instituições de garantir o acesso e sucesso dos seus jovens na qualidade de estudantes. Uma das questões centrais deste artigo é também compreender o tipo de relação que este grupo temcom a educação, a escola e com outras práticas educativas, incluindo os modos como estão a assegurar a continuidade da sua formação. Estávamos interessados em conhecer como vive este grupo esta situação do ponto de vista psicológico, mas sobretudo em produzir conhecimento informado sobre os modos como estão a ser educados conjuntamente com os desafios democráticos que a pandemia veio a trazer às instituições. Fomos atrás dos sentidos e da imagem da escola, incluindo os "rumos que a escola imprime na vida dos jovens" (ABRANTES, 2003, p. 7), num diálogo constante com os seus universos particulares.

É importante salientar que, ao contrário do que parece no senso comum, "crianças" e “jovens” são categorias cujas fronteiras definitórias não são autoevidentes nem emanam de uma materialidade biontológica, apesar de esta ser uma componente da sua definição. Conforme explica Daiane Valasques (2018), a definição sobre o que é ser criança e o que é ser jovem não dispõe de uma universalidade e varia entre diferentes áreas de saber, sociedades e culturas, com diferentes instituições e organismos a ter diferentes definições de infância e juventude ${ }^{\text {iii }}$. Como objeto privilegiado de múltiplos olhares (mediáticos, académicos, científicos, políticos, culturais, comerciais, etc.) que a descrevem e, simultaneamente, a produzem, infância e juventude são, pois, construções sociais nem sempre existentes enquanto conceitos problematizáveis em todas as sociedades e em todas as culturas, sendo as suas fronteiras 
definitórias de natureza oscilante e alvo da investida perpétua de diferentes grupos pela obtenção de poder e de controlo (ARIES, 1978; BOURDIEU, 1978; VIANNA, 1999).

No âmbito desta pesquisa, por razoes estratégicas de operacionalização, partilha-se da definição das Nações Unidas, também defendida pela instituição, em que criança e jovem partilham aspetos comuns. O nosso objetivo não é definir a criança e o jovem, a partir de uma delimitação temporal, mas compreendê-los a partir de fatores históricos, sociais e culturais, dentro de outros determinantes, como esses sujeitos se formam e se constituem, a partir das infinitas possibilidades de trocas e relações que estabelecem entre si e com os outros (VALASQUES, 2018).

\section{Metodologia}

Esta pesquisa exploratóriafoi conduzida entre março e maio de 2020 e emerge de um conjunto de preocupações com os efeitos da pandemia covid-19 com grupos tidos como vulneráveis, neste caso os jovens em situação de acolhimento residencial. Tínhamos como indagação principal uma questão tão simples quanto fundamental: como estão a viver estes jovens esta situação pandémica e como isso afeta (ou não) a sua experiência educacional.Os últimos dois meses têm sido intensos em crescentes e imediatistas apelos a estudos com base empírica sobre covid-19 em todo o globo, num movimento nunca visto de financiamento estratégico e produção científica articulada em massa. Contudo, a centralização de muitas dessas pesquisas no estudo das origens e impactos do vírus, acabou por privilegiar a pesquisa em áreas científicas das ditas "ciências naturais" como a Medicina, a Biologia, a Epidemiologia, entre outras, por oposição às ciências humanas e sociais, ao mesmo tempo que determinou uma clara predileção metodológica por abordagens quantitativas, concentradas em números, estatísticas e generalizações, e geralmente menos demoradas do ponto de vista da recolha e análise de dados ${ }^{\text {iv }}$.

Nesta pesquisa em Ciências da Educação, campo de estudos com uma expressiva tradição no uso de metodologias qualitativas (AMADO, FERREIRA, 2014), a intenção é oposta: queremos auscultar as vozes dos sujeitos nos seus próprios contextos para compreender os efeitos de uma pandemia que é, sobretudo, um desastre social. É, pois, necessário aceder aos modos como diferentes populações, comunidades e grupos sociais estão a viver estes conturbados tempos, o que é melhor respondido com aproximação aos contextos e ao discurso direto.Procurando transcender uma lógica mais formal, assente na inquirição pergunta-resposta, 


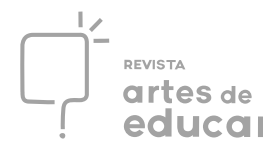

uma das opções foi uma abordagem participatória procurando envolver de forma significativa os jovens nos diferentes processos de tomada de decisão da pesquisa (MENEZES, FERREIRA, 2014), abordagem que permiteainda ir conhecendo os jovens e darmo-nos a conhecer.

\section{Participantes e recrutamento}

Tal como noutras pesquisas semelhantes (cf. FONSECA, 2017; VALASQUES, 2018), foi requisitada inicialmente a autorização da Direção da instituição para o acesso às instalações e recrutamento de participantes, o que se efetivou com a assinatura de um Protocolo de Consentimento e Colaboração. O envolvimento de jovens (e sobretudo de crianças) institucionalizadas em pesquisas científicas, por si só, de natureza intrusiva (BOURDIEU, 1997), exige um conjunto de cuidados éticos redobrados pela possibilidade de risco e exposição (cf. SILVA, 2013), não admirando ser difícil a concessão de autorização para a sua operacionalização. Terum elemento da equipa de pesquisa (o/a primeiro/a autor/a), que já tinha colaborado anteriormente com a instituição, facilita, pois, a aproximação e entrada no terreno como um contacto privilegiado. Proteger o anonimato é extremamente importante, mas extraordinariamente difícil, sobretudo em contextos relativamente destacados numa pequena comunidade em que instituições e pessoas podem ser facilmente identificadas. Desse modo, informações identificáveis não diretamente relevantes, como a região do país, foram apagadas. Pode-se, contudo, referir que a instituição se enquadra legalmente como uma IPSS (Instituição Particular de Solidariedade Social) e uma das suas respostas sociais é uma Casa de Acolhimento (Lar de Crianças e Jovens) que foi objeto do nosso interesse.

Com estatuto de utilidade pública, destina-se ao acolhimento de longa duração de crianças e jovens em situação de perigo com base na aplicação de medidas de promoção e proteção.No período de realização da pesquisa estavam sob sua responsabilidade 17 crianças e jovens que aceitarama participar sem exceção, o que se concretizou com a assinatura do Protocolo de Consentimento e Consensualidade. Todos foram informados sobre os objetivos do estudo e sobre as suas implicações e riscos assim como lhes foi esclarecido certas garantias como anonimato, sigilo e confidencialidade das respostas, assim como o facto de a sua participação ser voluntária, podendo os mesmos desistirem de participar da pesquisa sem penalização alguma. Em termos das suas caraterísticas, 8 jovens autoidentificavam-se como sendo do sexo masculino, e 9 jovens autoidentificavam-se como sendo do sexo feminino. $\mathrm{O}$ mais novo tinha 11 e a mais velha tinha 21 anos de idade. Todos os jovens frequentavam o 
ensino regular obrigatório em agrupamentos/escolas próximas do Concelho (do $7^{\circ}$ ano ao $12^{\circ}$ ), com a maioria a frequentarcursos profissionais (Cabeleiro, Restauração, Cozinha) como tende a ser habitual neste grupo de jovens (SILVA, 2011).

\section{Técnicas de recolha de dados}

Seguindo uma lógica "multimodal” (MANNAY, et al., 2018), utilizamos faseadamente três técnicas principais de recolha de dados, cada uma com um objetivo específico: photovoiced, entrevistas semiestruturadas e grupos focais.Como uma técnica fotográfica específica em que os participantes capturam as suas realidades quotidianas sob a forma de fotografias, o photovoiced permite dar voz à experiência pessoal através de um meio excecionalmente poderoso de comunicação - a imagem visual (WANG, BURRIS, 1997). Foi sugerido que tirassem fotografias a objetos, lugares ou situações que representassem o seu estado de espírito em relação à atual situação pandémica. Não se colocou limitações em relação ao número, mas explicitou-se que só iriam ser trabalhadas posteriormente uma fotografia e deixou-se bem claro evitar tirar fotografias a rostos, para preservar as identidades das pessoas. Não foi necessário distribuir máquinas fotográficas ou instruir as participantes sobre o seu uso, porque todas possuíam telefones portáteis com câmaras acopladas que sabiam manejar. Duas crianças mais pequenas que não tinham telemóveis utilizaram os telemóveis de seus irmãos. Embora em outras pesquisas, o photovoicedseja um método ou técnica estrutural e único, aqui foi mais utilizado como método contextualizado e exploratório.

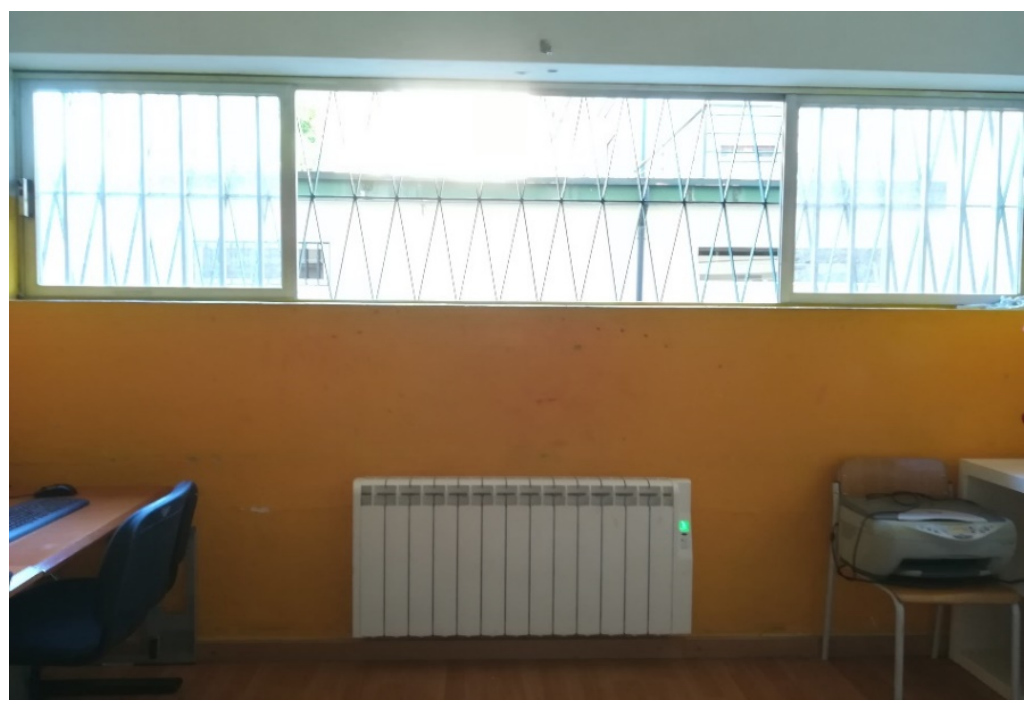

Essa foto foi tirada por uma das crianças da Casa de Acolhimento. A janela, na opinião da mesma, representa a visão do mundo lá fora: "Dá pra ver quem chega e quem sai da instituição. É um dos lugares que mais gosto de ficar." (E. Ana) 
Numa segunda fase, no início de abril, demos lugar às entrevistas de cariz semiestruturado cujo início começava precisamente pela exploração dos significados das fotografias de cada um. O objetivo das entrevistas era aceder diretamente a informações relacionadas com o objeto de estudo (AMADO, FERREIRA, 2014; BOURDIEU, 2001). Foi organizado o seguinte roteiro:

\begin{tabular}{|c|c|}
\hline Tópicos & Questões \\
\hline $\begin{array}{l}\text { Discussão da fotografia escolhida } \\
\text { Perceções }\end{array}$ & $\begin{array}{l}\text { - Quais são as perceções das crianças e } \\
\text { jovens sobre a situação atual e quais as } \\
\text { informações que tem disponíveis } \\
\text { sobre ela? }\end{array}$ \\
\hline Dificuldades e experiências educativas & $\begin{array}{l}\text { - Que dificuldades as crianças e jovens } \\
\text { enfrentam (se enfrentam) decorrentes } \\
\text { das medidas implementadas pelo atual } \\
\text { EE: } \\
\text { ○ quer a nível pessoal e } \\
\text { institucional, assim como na } \\
\text { sua relação com colegas, com } \\
\text { a família e com a instituição; } \\
\text { com a escola e restantes } \\
\text { atividades e experiências } \\
\text { educativas (e.g., online). }\end{array}$ \\
\hline Estratégias de resistência & $\begin{array}{l}\text { - A que estratégias recorrem para lidar } \\
\text { com esta situação excecional, qual o } \\
\text { papel da instituição neste processo, e } \\
\text { em que medida o conseguem fazer. }\end{array}$ \\
\hline
\end{tabular}

Sendo uma entrevista semiestruturada, tínhamos objetivos claros, mas queríamos dar espaço para que as crianças e jovens pudessem expressar as suas opiniões e tocarem em tópicos não inicialmente pensados. Muitas das questões foram formuladas consoante as respostas. Desse modo, o roteiro foi aplicado como se de uma conversa descontraída se tratasse com os participantes a discorreram livremente sobre os temas. Como se estava sobre o Estado de Emergência, algumas entrevistas foram realizadas via Zoom, com a ajuda de alguns técnicos, e 
demoraram em média 40 minutos. Algumas questões éticas específicas foram asseguradas nas entrevistas online como proibição de gravações em vídeo. Numa terceira e última fase, depois do desconfinamento, realizaram-se ainda dois grupos focais presenciais com os jovens divididos aleatoriamente em dois grupos de 8 e 9 elementos, num ambiente reservado, dentro da instituição, num contexto e com as condições mais familiares e naturais possíveis. Os grupos seguiram um script com questões abertas cujo tema central se basearam ora num cenário e expetativa pós-pandemia, ora em sugestões e recomendações para a melhoria das condições da instituição, sendo um tópico bastante focado nas entrevistas.

Como um processo dinâmico de influência bidirecional, onde pesquisadores e participantes são envolvidos numa forma colaborativa de pesquisa (cf. DIAS, MENEZES, 2013), os grupos focais são um método que potencializa a consciência e empoderamento coletivo, advogando a "ideia de que os problemas da comunidade devem ser discutidos entre todos/as do modo mais democrático possível" (SANTOS, SILVA, MENEZES, 2017, P. 121). Seguindo uma lógica participatória, um jovem da instituição agiu como facilitador/moderador liderando a discussão e procurando promover a expressão de uma ampla gama de pontos de vista e perspetivas num clima seguro e inclusivo e um outro tomava notas referentes ao comportamento físico dos participantes, havendo uma preocupação em ter dois elementos de géneros distintos para mitigar a influência das respostas, sabendo, porém, que tal nem sempre é possível.Como relembra Pierre Bourdieu, a pesquisa é sempre "uma relação social que exerce efeitos (...) sobre os resultados obtidos" (Bourdieu, 1997, p. 694), um jogo duplamente dissimétrico devido à detenção de capitais culturais de quem pesquisa (idem, p. 695). Em todas as fases do processo, procurou-se ainda cumprir escrupulosamente as regras sanitárias propostas em cada momento pela Direção-Geral da Saúde portuguesa como o cumprimento do distanciamento físico de 2 metros e o uso de luvas e máscaras.

\section{Análise dos dados}

Como uma abordagem qualitativa com foco ideográfico que procura identificar como um sujeito num dado contexto atribui sentido aos fenómenos, a análise fenomenológica interpretativa (IPA) parece-nos uma técnica adequadapara analisar os dados (NOON, HALLAM, 2018). Em termos analíticos, o processoenvolveu passos tidos como tradicionais: familiaridade com os dados através de leituras flutuantes, detalhadas e repetidas; identificação de unidades de significado e formulação inicial de códigos e classificação das unidades em 


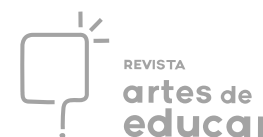

temas e subtemas, com o significado de cada categoria explicado e esclarecido. Optou-se por uma abordagem simultaneamente dedutiva e indutiva em que ao mesmo tempo que se procura obter uma compreensão mais profunda das questões de partida, permite-se que novas ideias emirjam. Após a chegada dos temas e subtemas, conversou-se com outros colegas investigadores para discutir e comparar as interpretações de modo cruzado de modo a interpretar os dados com mais claridade e imparcialidade. Todos os dados foram classificados, mas como se tinham objetivos de pesquisa claros, apenas dois temas foram para este artigo mobilizadas.

\section{Resultados e discussão}

As perspetivas dos participantes desenvolverem-se a partir de vários temase subtemas fundamentais. No âmbito deste artigo, foca-se dois temas em particular: (a) "Tá sempre a dar o «coronavírus...»: quotidianos «normais» em suspensos e (b) "Não temos computadores para todos!": experiências educacionais pautadas pela desigualdade. Na extensão de uma abordagem IPA, não há distinção explícita entre análise e redação na pesquisa. Como tal, invés de se optar por usar seções separadas de "resultados" e "discussão", com a primeira contendo as temáticas emergentes e a última vinculando a análise à literatura existente, procura-se antes compilar os dois elementos numa única secção de "resultados e discussão". De seguida, providenciamos uma descrição detalhada dessas categorias e subcategorias com excertos das sessões, para cada um dos grupos, apresentando e simultaneamente interpretando os dados, numa lógica entremeada.

\section{«Tá sempre a dar o «coronavírus...»: quotidianos «normais» em suspenso}

Além das informações prestadas pelos técnicos, é através da televisão, das pesquisas autónomas na internet (e.g., Google) e das redes sociais,como o Facebook,que os jovens vão acedendo a informações sobre o vírusSars-CoV ("eu ainda não sei bem, bem, o que é esse vírus, mas tipo, quando tenho tempo eu vou á net e vejo as notícias. Vou tando a par daquilo que tá a acontecer [E. Susana]; "Quando eu vou ver televisão, em vez de agora ver um filme, meto primeiro na CN [Correio da Manhã] e isso, e tá sempre a dar o Coronavírus..." [E. Beatriz].Pelas descrições, é notório que muitos dos jovens tem um constante acesso a informação através dos media digitais, sendo os seus quotidianos bombardeados por notícias 


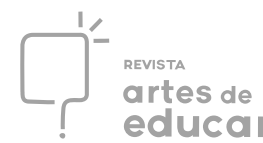

sobre o vírus. Há o reconhecimento de que se trata de uma situação invulgar que colocou os seus quotidianos «normais» em suspenso e que gera um conjunto alargado de sentimentos e emoções negativas: "Eu sinto-me insegura porque eu sei que posso apanhar. Porque há pessoas que entram aqui dentro que podem ir lá pra fora e que podem vir com o vírus e pode afetar todo mundo aqui dentro" [E. Anabela]. Ou:

Não tenho medo, mas é normal que sinta ansiedade pra sair e ver a família e tar com os amigos e poder ter a vida normal que todos nós tínhamos, né? Porque eu não sou a única.Aqui, tipo, eu tô segura. Mas, tipo, as pessoas que estão lá fora, que ainda trabalham, eu ainda tenho um bocado de medo, né?[E. Beatriz].

Quando interrogados sobre o modo como a pandemia afetou as suas vidas, os aspetos que os jovens mais identificam são o stress emocional devido ao distanciamento social, a interrupção das atividades letivas e restrições da liberdade de movimentos, incluindo atividades recreativas básicas, estando a atual situação pandémica a ser vivida com grande apreensão. Medo, ansiedade e insegurança figuram entre os principais sentimentos encontrados. Há medo em relação a ser infetado, diretamente ou através dos colegas, principalmente pelos profissionais (técnicos) que entravam e saiam dos turnos de trabalho, mas também o medo que o vírus infete os "seus", as suas famílias, sobretudo os idososv: "Eu tô bem, mas eu tenho medo que algumas pessoas da minha familia «ganhe», principalmente a minha vó, que já tem uma certa idade..." [E. Rute].Há também uma grande ansiedade que resulta da grande incerteza em relação ao futuro, sobre o fim da pandemia, mas também sobre os seus percursos. Se as expetativas destes jovens já eram marcadas por uma certa "desfuturização" (PAIS, 2003), isto é, a incapacidade de fazer planos em larga escala e projetar futuros com grandes perspetivas, o vírus veio a tornar mais evidente essa incapacidade. Todo este panorama é gerador de angústia que premeia os discursos destes jovens que confessam, muitas vezes, sentirem-se isolados e solitários, por vezes, entediados e com perda de individualidade:

Tô cá dentro, não posso ter as minhas coisas que eu gosto, que na minha casa gostava de ter, faz de conta, de beber coca colas... Não consigo, tô aqui dentro, já não faço nada que eu gosto. Não me sinto bem aqui dentro... Já não sou eu próprio [...] Isso é um bocado estúpido. Separam as mesas aí, separam as camas aí, mas cá embaixo estamos todos juntos...Cá dentro tamos sempre fechados, às vezes ficamos fartos de estar aqui dentro. Não é bom tá aqui dentro sempre fechado, tá sempre a ver televisão ... [E. Pedro]

Nestas circunstâncias, as crianças devem ser ajudadas a vencer a batalha interior que lhe permita planificar a sua vida futura e a orientá-la de acordo com um princípio de responsabilidade. (DELGADO, 2006, p. 84). A instituição assume aqui um papel redobrado de 


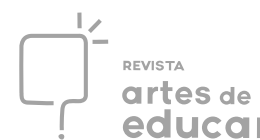

proteção do mundo exterior (VALASQUES, 2018), embora, por vezes, se reconheça que existem comportamentos questionáveis, pois, há jovens que cumprem as regras do confinamento, mas outros não("Depende muito. Uns obedecem, outros não tanto, saem, vão a festas e isso, agem como se estivesse tudo bem" [E. Leo]). Como justificativa para esse incumprimento, constituído por pensamentos de fuga e negação as regras instituídas pela instituição, com a de distanciamento social de seus pares e irmãos, está o tédio que se infiltrou nos quotidianos destes jovens que se sentem assim ainda mais enclausurados dentro da instituição,assim como uma certa racionalização sobre a incompreensível rigidez das normas.

Contudo, parte do incumprimento das regras deve ser lido não apenas como um ato de rebeldia contra as regras instituídas, mas, sobretudo, como uma necessidade cada vez maior de viver o momento presente (SILVA, 2011), o que nestes jovens, numa condição de impossibilidade de terem vidas planificadas, se torna excecionalmente apetecível. Há também claras diferenças de género nestes diferentes grupos, reconhecida pelos próprios. Enquanto as raparigas tendem a cumprir as normas, os rapazes arriscam mais:

\footnotetext{
Bia: - Os rapazes são piores, saem mais. Não querem saber, basicamente. Leo: - É muito chato estar aqui, temos que arejar... Bia: - Está a ver? É isto...

Benny: - Oh dizes isso porque para ti é fácil Bia, para nós não. Não há muitas coisas para fazer aqui, é uma seca, bazamos, ora...[GDF2].
}

A necessidade de muitos rapazes extravasarem torna-se um aspeto bastante referido num contexto onde o risco esta cada vez mais presente. Aproveitar o momento adquire neste contexto uma significância cada vez maior. De facto, as raparigas tendem a enveredar mais por uma "cultura de quarto" (CARDOSO, 2012) que as beneficia mais pois podem dedicar-se mais aos estudos e explica, em parte, o seu investimento educacional (FONSECA, 2002). Já para os rapazes estar "em casa", na instituição, é aborrecido e entediante, e sentem que tem que sair, extravasar, "bazar". Desse modo, os rapazes enveredam mais por uma "cultura de risco" queé parte do caldo cultural que sustenta as suas performances genderizadas de masculinidade hegemónica. Alguns rapazes chegavam mesmo a explicar que lavar as mãos ou usar luvas é "uma mariquice", o que mostra claramente como o género e a masculinidade tóxica explicam certos aspetos de (não-)reconhecimento e (in)cumprimento das regras (SANTOS, SILVA, MENEZES, 2017).

Estar na instituição em contexto de pandemia é então visto por estes jovens com um sentido paradóxico: por um lado, reconhecem que estar na instituição significa estarem protegidos, em segurança, acabando por admitir estreitar mais os laços com os colegas e 
elementos da instituição; por outro lado, sentem-se enclausurados, fechados, lamentando a sua falta de liberdade e individualidade, o que é excecionalmente sufocante para estes jovens institucionalizados, de si impedidos das mesmas liberdades que outros.

\section{"Não temos computadores para todos!": experiências educacionais pautadas pela desigualdade}

Uma outra dimensão discutida foram as experiências educacionais destes jovens e o modo como as viviam. Embora concordem, genericamente, que a decisão temporária de fechar as escolas foi uma medida apropriada para conter a propagação da doença, enfatizam o impacto negativo que isso teve nas suas rotinas diárias de aprendizagem ${ }^{\mathrm{vi}}$. Quer nas entrevistas individuais, quer nos grupos focais, há um certo consenso de como a atual situação torna insustentável uma relação saudável e sustentável com a aprendizagem (CUEVAS-PARRA, STEPHANO, 2020): “É uma situação difícil. Antes, as escolas estavam abertas, íamos para a escola aprender e tudo fixe. Agora, de repente o vírus veio, e tudo parou [E. André].Com a pandemia, uma das soluções encontradas, também na instituição, foi, além da Telescola, as aulas online através da Zoom. Todos os jovens estudantes, em diferentes horários, têm acesso às aulas virtuais que se apresenta como uma das plataformas mais usadas (ARCHIBALD,et al., 2019). Contudo, nem todos se sentem confortáveis neste registo, por diversas razões:

As aulas agora são por vídeo chamada e os professores tentam explicar ao máximo, só que não é a mesma coisa de tarmos dentro de uma sala de aula, os professores a explicarmos, porque é melhor [...]. Nós temos aula igual pela RTP, mas ter aulas com os professores mesmo, é melhor. Os professores já podem explicar melhor. A dúvida de um, pode ser a dúvida do outro. [E. Bia].

Para muitos jovens, estas modalidades de e-learningsão desinteressantes e geradoras de uma desmotivação geral, sendo apresentado vários motivos para tal desinvestimento.Uma das razões é o desgaste que as sessões online implicam. Quando um dos componentes da comunicação está ausente ou limitado, emissor e recetor se veem obrigados a prestar mais atenção e a fazer um esforço maior para se expressar e para entender corretamente um ao outro, o que exige um esforço que provoca tensão em quem não está acostumado, aumentando os níveis de stress e exaustão emocional. Pesquisas vêm mostrando que a aprendizagem por meios eletrónicos exige muito maior concentração e é muito mais desgastante das funções cognitivas, especialmente da atenção (cf. COSTA, 2010). Uma outra frustração identificada eram as dificuldades em seguir as lições, responder a tarefas online ou tirar dúvidas, muito mais difícil 
via Zoom, com alguns jovens referindo ainda a impreparação de professores e educadores em manusear as tecnologias digitais na sua passagem para o ensino a distância ("Eles se esforçam, mas tipo, o meu profe não sabe o que é o TikTok, o que é o Skype, é complicado... [E. Rui]), geralmente tratando-os como infoexcluídos ou tecnófobos, em especial os mais velhos.

Contribuem para o cenário o facto de muitos técnicos não terem formação sobre mediação de aulas e contexto de sala virtual, prestando pouco apoio tutorial durante ou depois da aula ( "ajudam, mas nem sempre; às vezes temos que ser nós” [E. Bia]). Regra geral, há um discurso em que se tende a enfatizar a importância que o ensino em contexto de sala de aula tem por oposição ao ensino à distância, mais frio e clínico, partilhando-se da ideia de que ensino presencial é uma parte central da experiência de aprendizagem. Ir à escola é também um pretexto para estar com colegas e amigos, conversar, socializar, brincar, almoçar, festejar, etc., e todas essas atividades fazem parte de uma experiência holística que não se pode ser replicada ou mimetizada via online (Lang, 2016), muito menos em disciplinas ou aulas com uma forte componente prática("Educação Física e isso não temos, é impossivel, e na Telescola é a tragédia que se ve... [E. Rui]).

Outras questões como as dificuldades de concentração, facilidade de distração, parca produtividade (e.g., no estudo e nos trabalhos de casa), procrastinação, a erosão entre vida privada e escolar e a acumulação de trabalhos, foram discutidas com os jovens como obstáculos ao sucesso das modalidades de educação online. As crianças e jovens, em situação de acolhimento residencial, buscam na escola um espaço de acolhimento e inclusão. O professor é um agente-chave no processo de ensino-aprendizagem dessas crianças e jovens, pois, pode aproximar-se, criar um vínculo afetivo e ser instrumento a serviço do crescimento do aluno (VALASQUES, 2018), mas, grosso modo, há um empobrecimento da troca direta de experiência entre professor e aluno que compromete a relação e prática pedagógica.

Nos grupos focais, um ponto de discussão foi a erosão entre a vida privada e as obrigações educacionais via online, geralmente com os jovens a queixarem-se de como tem pouco espaço para se dedicar às tarefas que mais gostam. O direito a brincar, ao lazer e aos tempos livres é uma reivindicação que surge, muitas vezes, em discurso. Como refere Daiane Valasques,

uma institucionalização só será instrumento de (re)inserção e socialização, quando perceber a criança e o jovem dentro do seu contexto familiar, comunitário e social e a partir de suas individualidades, de género, de raça, de cultura, etc. Fechar a criança ou jovem em quatro paredes, vigiá-la e querer controlar suas atitudes é 
diminuir o que a criança e o jovem têm de mais importante que é a sua capacidade de aprender com o outro (VALASQUES, 2018, p. 44).

Em todo o caso, é interessante verificar que, contrariamente àquilo que é sugerido por alguma literatura (cf. ABRANTES, 2003; SILVA, 2011), muitos destes jovens sentem saudades das suas rotinas diárias e atribuem bastante relevância à escola, sobretudo como um lugar significativo de convívio e de sociabilidade (LAHELMA, 2002).Embora possuam percursos e envolvimentos educacionais muito variáveis e dispares assim baixo desempenho escolar, demonstram uma "visão positiva da escola" (FONSECA, 2017, p. 293), revelam bastante empenho nas atividades escolares e tem expetativas altas em relação ao seu sucesso escolar e profissional, com destaque para as raparigas (FONSECA, 2002).

Enquanto que os primeiros obstáculos de adesão à educação via Zoom parecem ser intrínsecos à educação virtual, outros relacionam-se intimamente com as condições estruturais da instituição e com os modos como ela garante ou não a igualdade de oportunidades a estes jovens.Referencia-se bastante a escassez de recursos disponibilizado pela instituição, seja ao nível da falta das infraestruturas dignas - neste aspeto, são referenciados a falta de salas e espaços assim como problemas acústicos -, seja a falta de recursos tecnológicos, neste caso, computadores (fixos ou portáteis) e acesso de qualidade à internet (cabo ou WI-FI), que determinam e limita negativamente uma educação de qualidade. Neste ponto, os jovens não tem receio de assumir uma voz muito crítica:

Primeiro, na sala de estudo, a porta não fecha. Logo, as pessoas entram e saem quando querem e deixam a porta aberta. Os miúdos berram pra um lado os miúdos berram pro outro, enfim... Depois temos dois PCs, neste caso o meu, né? Que foi emprestado pela escola, mas que também não tá a funcionar muito bem. A Doutora já ligou pra trocar o PC... [GDF2, Ana].

Se eu tivesse em casa eu tinha feito tudo até agora, sinceramente. Participava nas aulas, porque lá em casa, principalmente, tenho o meu próprio computador. Segundo, tenho silêncio, que é uma das coisas que eu mais gosto. Sinceramente, uma das principais dificuldades, é mesmo estar aqui dentro... tá sempre a ouvi barulho, isso incomoda-me imenso [...] O computador é que às vezes não dá, a internet falha, é lenta." [E. Rui].

Ter um só computador ao dispor de todos é algo referido comumente como um constrangimento para a maioria destes jovens nesta instituição em particular. Este tipo de limitação é possivelmente excarcerada em comunidades em que as opções para a aprendizagem remota não estão disponíveis ou é providenciada, deixando os estudantes sem alternativa para continuar a aceder e a estudar durante a quarentena (CUEVAS-PARRA, STEPHANO, 2020), e claramente permite-nos indagar os direitos destes jovens a ser educados. $\mathrm{Na}$ verdade, 
frequentemente os jovens destacavam como havia certas carências na instituiçãocomo a falta de técnicos e consequentemente de atividadeslúdicas motivadoras:

Às vezes as pessoas que podiam tár ao nosso lado, acompanhar melhor, por exemplo, às vezes, temos falta de monitores à tarde. As vezes, eu tenho trabalhos, minha irmã também tem, e outros utentes também têm e só há um funcionário [...] Poderiam fazer mais atividades e ter mais funcionários, porque aqui há poucos funcionários [João, GDF1]

Queixam-se ainda de alguma falta de apoio mais específico (na orientação das sessões online, por exemplo) assim como da falta de formação dos técnicos para lidar com as novas tecnologias da informação e comunicação. Ainda assim, não deixam de reconhecer o papel incontornável dos técnicos existentes que em tempos de pandemia acabam por prestar um apoio incontornável.Estas relações de cuidado e amizade "pois estão diretamente relacionadas à autoestima e ao bem-estar, proporcionando aos adolescentes o apoio emocional necessário para que eles possam lidar com eventos geradores de estresse, a exemplo de doença ou perda de familiares" (FONSECA, 2017, p. 287). Mais uma vez se reforça como a construção de sentido de pertença à instituição é marcado pela ambiguidade: por um lado, são bastante críticos de muitos seus aspetos e modos de funcionamento. Contudo, não deixam nunca de reconhecer a relevância medular que esta tem na sua formação enquanto indivíduos (VALASQUES, 2018) ao mesmo tempo que se recusam a confinarem-se ao estatuto inglório de vítimas passivas.

\section{Conclusão}

A pandemia Covid-19 veio a questionar as estruturas mais fundacionais das nossas sociedades, o que inclui as nossas democracias, expondo-nos a uma precariedade generalizada (BUTLER, 2015). Isto é particularmente grave para os jovens em situação de acolhimento residencial que já estão numa situação de excecional vulnerabilidade, ainda que sejam menos auscultados no que concerne ao seu bem-estar individual e coletivo. De si, as crianças e os jovens já são objeto de representações contraditórias, quer como agentes de construção de futuro, quer como "um problema" (SILVA, 2011, p. 38), e portanto, é preciso interpelar os seus discursos. Visando conhecer o modo como estão a viver esta situação, esta pesquisa, com base numa abordagem participatória, demonstra que os jovens se sentem isolados e entediados, embora alguns arriscam em incumprir as regras. Esta conceção vai ao encontro de José Machado Pais (2006), de que os jovens procuram fugir às tentativas regulatórias e prescritivas 
que se esperam deles e no caso da pandemia não seria diferente. Num mundo cada vez mais desfuturizado, procuram viver o dia-a-dia.

Do ponto de vista educacional, a educação online está a ser levada a cabo, mas as suas experiências de aulas online são particularmente fracassadas. Os jovens queixam-se de cansaço, e anseiam o regresso ao ensino presencial, revelando como a escola é, apesar de tudo, um lugar apetecido (LAHELMA, 2002). Apesar de encararem a instituição como um lugar protetor, revelam alguns aspetos críticos em relação à falta de condições e recursos que esta tem ao dispor para tornar o ato educativo mais apelativo e útil, nomeadamente ao nível das infraestruturas e tecnológicos. Desse modo, a crise pandémica veio revelaralguns problemas estruturais destas instituições que, apesar dos esforços, tem de se deparar com falhas e lacunas que suprimidas dariam mais alento às suas missões educativas. A própria tendência e pressões para a desinstitucionalização acaba por contribuir para um certo desinvestimento político e social.

Como defendem Tomas, Carvalho e Fernandes (2019), o crescimento do número de jovens adolescentes com problemas de comportamento e de saúde mental exige um conjunto de recursos especializados e um investimento das comunidades e decisores/as políticos/as que venha a traduzir-se numa maior eficácia das respostas implementadas, restruturações e modernizações das práticas de atuação.

Com o aumento do número de crianças e jovens nestas condições torna-se imperativo repensar as conceptualizações e práticas subjacentes ao acolhimento assim como as políticas públicas e respostas sociais fazendo desta uma área em necessidade de permanente evolução e atualização, sabendo, porém, que as políticas de juventude devem antever que "as trajectórias dos jovens são complexas, mas porque elas decorrem em terrenos labirínticos" (PAIS, 2006, p. 64). O investimento em recursos tecnológicos e na melhoria das condições gerais de aprendizagem é urgente e como sugere Daniel (2020), deve-se pensar uma maior articulação entre modalidades de ensino à distância e ensino presencial num futuro pós-pandemia.

Metodologicamente, os dados gerados com esta pesquisa não podem nem pretendem servir para futuras generalizações.Trata-sede conhecimento bastante contextualizado que só pode ser compreendido quando analisado em si mesmo (AMADO, FERREIRA, 2014). Contudo, contribui para a teoria em expansão, e em particular para os estudos educativos sobre juventude, educação e Covid-19, previsivelmente em clara ascensão. A particularidade na utilização de metodologias participatória é de especial valor pois ao passar a envolver efetivamente as crianças e jovens na tentativa de resolução dos problemas que os afeta, sentidos de pertença e reconhecimento mais fortes são construídos na instituição (MANNAY, et al., 


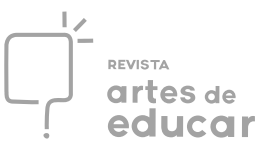

2019; SILVA, 2011; TOWNSEND, BERGER, REUPERT, 2020).Não se trata ainda de uma "participação transformatória" (DISKALL, 2013) - sendo, pois, preciso aprofundar mais as lógicas interventivas, incluindo comunitariamente -, mas lança-se as sementes para novas possibilidades de agenciamento.

Ainda assim, não se pode deixar de terminar com uma palavra de esperança. Uma vez que a palavra “crise"voltou à discursividade pública, é preciso reconhecer os seus significados mais recônditos para avaliar a atual situação. Se nos ativermos na sua origem etimológica “crise" vem do latim e significa "momento de decisão súbita e crucial” (ZIZEK, 2020).Ora, que esta crise pandémica seja, pois, uma oportunidade de ouro para a mudança e transformação social.Desse modo, acreditamos que este trabalho possa contribuir para uma reflexão sobre a singularidade dos sujeitos que se acolhem em instituições, das suas necessidades básicas, afetivas, sociais e escolares. A criança ou jovem deve ser percebido, a todo instante, como sujeito de direitos e deveres que precisa, nesses espaços, ter a possibilidade de se desenvolver com igualdade e equidade.

\section{Referências}

ABRANTES, P. Os sentidos da escola. Identidades juvenis e dinâmicas de escolaridade. Oeiras: Celta Editora, 2003.

AMADO, J; FERREIRA, S. A entrevista na investigação em educação. In: AMADO, J. (Coord.). Manual de investigação qualitativa em educação. Coimbra: Impresa da Universidade de Coimbra, 2014, p. 207-232.

ARAÚJO, H. C.; WILLIS, P. Jovens, percursos e transições em instituições e comunidades educativas. Uma revisitação na Grã-Bretanha e em Portugal. Educação, Sociedade e Culturas, $\mathrm{n}^{\mathrm{o}} 27$, p. 7-13, 2008.

ARCHIBALD, M.; AMBAGTSHEER, R; CASEY, M.; LAWLESS, M. Using Zoom videoconferencing for qualitative data collection: Perceptions and experiences of researchers and participants. International Journal of Qualitative Methods, 18, p. 1-8, 2019.

ARIÈS, P. História social da infância e da família. Tradução: D. Flaksman. Rio de. Janeiro: LCT, 1978.

BECKER, H. S.Whose side are we on? Social Problems, Vol. 14, No. 3, p. 239-247, 1967.

BOURDIEU, P. Compreender. In: BOURDIEU, P. (Coord.). A miséria do mundo. Petropólis: Editora Vozes, 1997, p. 693-732. 
BOURDIEU, P. “La «jeunesse» n'est qu'un mot”. Entretien avec Anne-Marie Métailié, paru dans Les jeunes et le premier emploi. Paris, Association des Ages, 1978, p. 520-530.

Disponível em: http://www.homme-

moderne.org/societe/socio/bourdieu/questions/jeuness.html, 30/05/2013. Acesso em: 30 jun. 2020 .

BOURDIEU, P; PASSERON, J-C. A Reprodução: Elementos para uma Teoria do Sistema de Ensino. Lisboa: Editorial Veja, 1983.

BUTLER, J. Quadros de guerra. Quando a vida é passível de luto? Rio de Janeiro: Civilização Brasileira, 2015.

CARDOSO, D. A cultura do quarto e o uso excessivo da internet. Resultados nacionais do inquérito EU Kids Online. In: PONTE, C.; SIMÕES, J. A.; JORGE, A.; CARDOSO, D. (Eds.), Crianças e Internet em Portugal. Acessos, usos, riscos, mediações: Resultados do Inquérito Europeu EU Kids Online. Coimbra: Edições Minerva, 2012.p. 57-73.

COSTA, E. Avaliação da integração de plataformas e-learning no ensino secundário. 2010.Tese de Doutorado em Ciências da Educação. Universidade Salamanca, Salamanca, 2010 .

CUEVAS-PARRA, P.; STEPHANO, M. Children's voices in the time of COVID-19. Continued child activism in the face of personal challenges. Middlesex: World Vision International, 2020.

DANIEL, S.J. Education and the COVID-19 pandemic. PROSPECTS, 2020. Disponível em: $<$ http://link.springer.com/10.1007/s11125-020-09464-3>. Acesso em: 4 maio 2020.

DELGADO, P. Os direitos da criança: da participação à responsabilidade. Porto: Profedições, 2006.

DIAS, T. S.; MENEZES, I. The role of classroom experiences and school ethos in the development of children as political actors: Confronting the vision of pupils and teachers. Educational \& Child Psychology, Vol. 30, No. 1, p. 26-37, 2013.

FONSECA, L. Revisitando culturas juvenis: Investimento de raparigas na escola.ex aеquo, $n^{\circ} .7$, p. 85-98, 2002.

FONSECA, P. N. da. O impacto do acolhimento institucional na vida de adolescentes. Revista Psicopedagogia, 34(105), p. 285-296, 2017.

GOFFMAN, E. Manicômios, prisões e conventos. São Paulo: Editora Perspectiva S.A, 1961.

GOFFMAN, E. On cooling the mark out. Some aspects of adaptation to failure. Psychiatry, Interpersonal and Biological Processes, Vol. 15, Issue 4, p. 451-463, 1952.

LAHELMA, E. School is for meeting friends: secondary school as lived and remembered.British Journal of Sociology of Education, vol. 23, nº. 3, p. 367-381, 2002. 
LANG, J. Small teaching: Everyday lessons from the science of learning. San Francisco: Jossey-Bass, 2016.

LUDVIGSSON, J. F. Systematic review of COVID-19 in children shows milder cases and a better prognosis than adults. Acta Paediatrica, 109, p. 1088-1095, 2020.

MANNAY, D.; STAPLES, E.; HALLET, S; ROBERTS, L;REES, A; EVANS, R; ANDREWS, D..Enabling talk and reframing messages: working creatively with care experienced children and young people to recount and re-represent their everyday experiences, Child Care in Practice, 25(1), 51-63, 2019.

MENEZES, I.; FERREIRA, P. D. Cidadania participatória no quotidiano escolar: A vez e a voz das crianças e dos jovens. EducaremRevista, 53, p. 131-147, 2014.

NOON, E.; HALLAM, S. Interpretive Phenomenological Analysis: An appropriate methodology for educational research? Journal of Perspectives in Applied Academic Practice, Vol 6, Issue 1, p. 75-83, 2018.

PAIS, J. M. Jovens e Cidadania.Sociologia, Problemas e Práticas, n. o 49, p. 53-70, 2006.

PAIS, J. M. The multiple faces of the future in the labyrinth of life. Journal of Youth Studies, v. 6, n. 2, p. 115-126, 2003.

RELATÓRIO CASA. Relatório de Caracterização Anual da Situação de Acolhimento de Crianças e Jovens, 2016. Disponível em: http://www.segsocial.pt/documents/10152/15292962/Relatorio CASA 2016/b0df4047-13b1-46d7-a9a7f41b93f3eae7 Acesso em: 29 jun. 2020.

SANTOS, H; SILVA, S. M. da; MENEZES, I. Para uma visão complexa do bullying homofóbico: Desocultando o quotidiano da homofobia nas escolas. ex aequo, 36: 117-132, 2017.

SILVA, S. M.Young people and sensitive information: Managing protection and dignity. In: RIELE, K; BROOKS, R. (Eds.), Negotiating ethical challenges in youth research. London/New York: Routledge, 2013, 96-108.

SILVA, S. M. Da casa da juventude aos confins do mundo: Etnografia de fragilidades, medos e estratégias juvenis. Porto: EdiçõesAfrontamento, 2011.

SPIVAK, G. C. Can the Subaltern Speak?In: NELSON, C; GROSSBERG, L. (Eds.), Marxism and the Interpretation of Culture. Basingstoke: Macmillan Education, 1988, p. 271-313.

TISDALL, E.K.M.The transformation of participation? Exploring the potential of 'transformative participation' for theory and practice around children and young people's participation. Global Studies of Childhood, 3(2), p. 183-193, 2013.

TOMÁS, C; CARVALHO, M. J. L. de; FERNANDES, N. Introdução - Acolhimento de Crianças e Jovens. Configurações, vol. 23, p. 7- 13, 2019. 


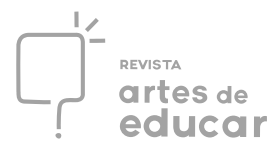

TOWNSEND, I. M.; BERGER, E. P.; REUPERT, A. E.Systematic review of the educational experiences of children in care: Children's perspectives. Children and Youth Services Review 111, 104835, p. 1-10, 2020.

UNESCO. UNESCO Covid-19 Education Response Education Sector Issue Notes. Paris: UNESCO, 2020a. Disponível em: https:/en.unesco.org/covid19/educationresponse. Acesso em: 1 jun 2020.

UNESCO. Supporting teachers in back-to-school efforts: guidance for policy-makers. Paris: UNESCO, 2020b. Disponível em: https://unesdoc.unesco.org/ark:/48223/pf0000373479 Acesso em: 1 jun. 2020.

VALASQUES, D. De uma situação de risco para uma vida de cidadania: um estudo exploratório sobre a proposta educativa da Casa do Gaiato de Paço de Sousa. Dissertação de Mestrado em Ciências da Educação. Universidade do Porto, Porto, 2018.

VIANNA, A. O mal que se adivinha: polícia e menoridade no Rio de Janeiro, 1910-1920. Rio de Janeiro: Arquivo Nacional, 1999.

WANG, C; BURRIS, M. A. Photovoice: concept, methodology, and use for participatory needs assessment. Health Education \&Behaviour, 24(3), 369-387, 1997.

WILLIS, P. Learning to labour. How working-class kids get working class jobs. Aldershot: Ashgate, 1999.

ŽIŽEK, S. Pandemia. Covid-19 e a Reinvenção do Comunismo. Editorial Boitempo, 2020.

\footnotetext{
${ }^{\mathrm{i}}$ Doutoranda em Estudos da Criança, pelo Instituto de Educação da Universidade do Minho (PT). Mestra em Ciências da Educação, pela Faculdade de Psicologia e de Ciências da Educação da Universidade do Porto (PT). Licenciada em Pedagogia e Especialista em Alfabetização e Letramentos, pela Universidade Estadual do Sudoeste da Bahia (BRA). E-mail: daianevalasques@hotmail.com .ORCID https://orcid.org/0000-0002-4623-2160

ii Doutor em Ciências da Educação pela Faculdade de Psicologia e de Ciências da Educação, Porto, Portugal. Membro Colaborador do CIIE - Centro de Investigação e Intervenção Educativas. E-mail: hugosantos@,fpce.up.pt. ORCID https://orcid.org/0000-0003-2808-9863

iii Por exemplo, as Nações Unidas definem “jovem” como todos aqueles que se situam entre os 15 e os 24 anos de idade, enquanto que a Organização Mundial de Saúde começa a contagem a partir dos 10. Fazendo uma distinção entre criança e adolescente, a lei brasileira, por exemplo, considera criança a "pessoa até doze anos de idade incompletos" e adolescente "aquela entre doze e dezoito anos de idade". Para a Associação de Crédito Agrícola portuguesa, o limite da juventude estende-se até aos 40 e para Convenção dos Direitos da Criança não existe sequer o conceito de jovem, apenas o de criança que é todo aquele indivíduo que vai até 18 anos de idade.

iv Pela sua natureza, exige mais tempo do que as análises estatísticas ou métodos quantitativos, ao nível do recrutamento e acompanhamento dos/as participantes, requisição de autorizações institucionais e éticas, operacionalização do método de recolha de dados, reflexões na conceptualização da pesquisa, análise de dados, sua leitura e compreensão integrativa. Como o vírus é recente e as pesquisam científicas e académicas precisam de algum intervalo de tempo de operacionalização (reflexão, recolha, análise e publicação), não é de admirar que ainda sejam residuais os estudos.

${ }^{\vee}$ Verifica-se que neste Lar, à semelhança do que acontece noutros contextos (FONSECA, 2017; VALASQUES, 2018), os jovens mantêm vínculos com familiares e amigos por meio de visitas, telefone e redes sociais.

${ }^{\mathrm{vi}}$ As crianças só passaram a ter vistas e a poder sair e ir a casa somente no dia 19 de junho. Isso demostra a demora de respostas dos órgãos responsáveis às instituições de acolhimento. Comparado as aulas no secundário que começaram no 18 de maio e as creches que abriram no dia 01 de junho.
} 